\title{
Estudo preliminar de paradigma de estresse predatório para indução de ansiedade em camundongos Swiss
}

Joyce Moreira de Souza ${ }^{1}$, Sabrina Ferreira de Almeida ${ }^{2}$, Bruna de Oliveira Mendes ${ }^{2}$, Bianca Costa e Silva ${ }^{2}$, Wellington Alves Mizael da Silva ${ }^{1}$, Abraão Tiago Batista Guimarães ${ }^{1}$, Raíssa de Oliveira Ferreira ${ }^{2}$, Dieferson da Costa Estrela ${ }^{2,3}$, Guilherme Malafaia ${ }^{1,2,3,4 *}$

1 Programa de Pós-Graduação em Conservação de Recursos Naturais do Cerrado. Instituto Federal Goiano - Câmpus Urutaí, GO, Brasil. ${ }^{2}$ Laboratório de Pesquisas Biológicas. Instituto Federal Goiano - Câmpus Urutaí, GO, Brasil.

${ }^{3}$ Departamento de Ciências Biológicas. Instituto Federal Goiano - Câmpus Urutaí, GO, Brasil.

4Programa de Pós-Graduação em Biodiversidade Animal, Universidade Federal de Goiás, GO, Brasil. *Autor para correspondência: guilhermeifgoiano@gmail.com

\section{N F O A R T I G O}

\section{Histórico do artigo}

Recebido: 20 janeiro 2016

Aceito: 10 abril 2016

Palavras chaves:

Modelos experimentais

Labirinto em cruz elevado

Estresse predatório

Camundongos

Ratos

\begin{abstract}
A B S T R A C T
In this study we modified the predatory stress paradigms to determine if a simple and new predatory stress paradigm could produce anxiety-like behaviour in female Swiss mice, exposed to male Wistar rat. We hypothesized that the stressor employed would induce anxiety in the short-term in mice. In addition, we assessed the behavioral effects of the paradigm as much as 12 days after the conclusion of the stress exposure and demonstrate lasting effects of the predatory stress exposure on behavior. Collectively, the data presented here demonstrate that the rat-on-mouse predatory stress paradigm causes changes in behavior of female Swiss mice following a 12 day exposure to the chronic stress paradigm.
\end{abstract}

\section{Introdução}

A ansiedade é um distúrbio psíquico que acomete grande parte da população, podendo estar relacionado à elevadas cargas de estresse. Alguns estudos têm buscado induzir ansiedade em modelos experimentais com o intuito de estudar e compreender a etologia desse distúrbio afim de buscar possíveis tratamentos (Nunes \& Hallak, 2014; Guimarães et al., 2016). Os estressores utilizados na maioria dos estudos são estressores físicos como: choques elétricos, restrição e resfriamento. Um fator estressante muito eficiente é o estresse predatório, o qual induz respostas similares àquelas ocorridas no ambiente natural, em que o animal está exposto à visão, audição e odor de seu predador (Burgado et al., 2014). Muitos estudos observaram alterações comportamentais e fisiológicas ocasionadas pela exposição ao stress predatório (Adamec et al., 2006; Miura et al., 2011; Guimarães et al., 2016).

Nesse sentido, estudos têm utilizado ratos como predadores e camundongos como presas, induzindo nestes últimos comportamentos preditivos de ansiedade e permitindo estudos mais específicos em condições laboratoriais. Burgado et al. (2014) observaram que duas semanas de estresse predatório (ratos Long Evans machos, como estressores) induz comportamento preditivo de ansiedade associado à comportamento preditivo de depressão em machos adultos de camundongos C57BL/6J. Miura et al. (2011) utilizaram um protocolo de estresse complexo que incluía contenção e estresse predatório e que, surpreendentemente, não foi capaz de induzir comportamento ansiogênico em camundongos. Já Guimarães et al. (2016) demonstraram que um protocolo simples de estresse predatório em curto período de exposição é capaz de induzir comportamentos de ansiedade em camundongos. Tais divergências apontam para a necessidade de testar diferentes condições, afim de melhor compreender este paradigma comportamental. Os modelos de estresse predatório induzem medo e irritabilidade nas presas, contudo, os estudos submetem tais presas coletivamente aos protocolos, fato que pode contribuir para uma maior resistência aos agentes estressores por parte das presas.

Dessa forma, neste estudo é levantada a hipótese de que camundongos Swiss expostos a um protocolo de estresse predatório, utilizando ratos Wistar como estressores, individualmente podem desenvolver comportamentos preditivos de ansiedade de forma mais eficiente que quando submetidos coletivamente, uma vez que o isolamento configura um estressor a mais no protocolo. 


\section{Material e métodos}

\subsection{Animais}

Foram utilizadas fêmeas de camundongos Swiss obtidas a partir de matrizes provenientes do Biotério Central da Universidade Federal de Goiás (Goiânia, Goiás, Brasil) e mantidas no biotério do Laboratório de Pesquisas Biológicas do Instituto Federal Goiano - Câmpus Urutaí (Urutaí, Goiás, Brasil). Durante o período experimental, os animais foram submetidos a ciclo natural claro/escuro (aproximadamente 12:12 horas), e ofertados ração e água ad libitum.

Animais com 21 dias de idade foram distribuídos em seis grupos com 10 indivíduos cada: controle individual (CI) e controle coletivo (CC) (ambos com animais expostos individualmente e coletivamente a uma caixa escura sem o predador, respectivamente); ratoeira sem estresse predatório individual (RI) e ratoeira sem estresse predatório coletivo (RC) (ambos com os animais dentro de uma ratoeira, e esta dentro da caixa escura sem o predador, individualmente e coletivamente, respectivamente) e; estresse predatório individual (EPI) e estresse predatório coletivo (EPC) (ambos com animais expostos à ratoeira, caixa escura e um rato Wistar (predador) de forma isolada e coletiva, respectivamente).
A metodologia deste estudo foi considerada consistente com os princípios éticos para experimentação animal e aprovado pela Comissão de Ética no Uso de Animais do Instituto Federal de Educação, Ciência e Tecnologia Goiano, GO, Brasil (protocolo n. 18/2014). Foram feitos todos os esforços para minimizar tanto o número de animais utilizados quanto o grau de seu sofrimento.

\subsection{Protocolo de estresse predatório}

Para induzir o estresse predatório nos grupos EPI e EPC, os camundongos foram colocados em uma ratoeira $(21,5$ $\mathrm{cm} \times 11,5 \mathrm{~cm} \times 29,0 \mathrm{~cm}$ ) protegida com tela metálica (com malha de 5-mm) e esta colocada dentro de uma caixa maior $(39,5 \mathrm{~cm} \times 34,0 \mathrm{~cm} \times 58,0 \mathrm{~cm})$ contendo um rato macho (adulto) da linhagem Wistar e baixa luminosidade. Estes ratos são predadores naturais de camundongos e constituíram o agente estressor neste experimento. 0 aparato foi construído de modo a evitar que os camundongos fossem predados pelos ratos Wistar (Figura 1). Os camundongos dos grupos CI e CC foram submetidos à caixa escura sem as ratoeiras e os grupos RI e RC foram submetidos às mesmas condições experimentais de EPI e EPC, sem a presença de ratos Wistar.

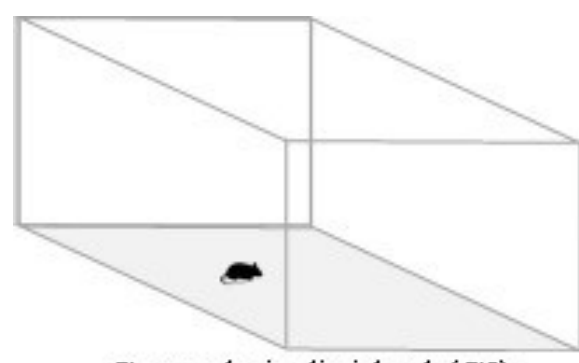

Controle individual (CI)

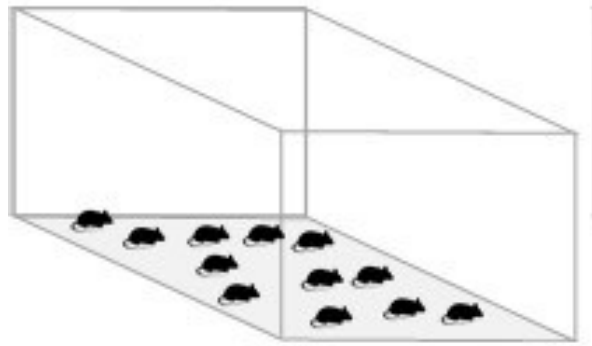

Controle coletivo (CC)

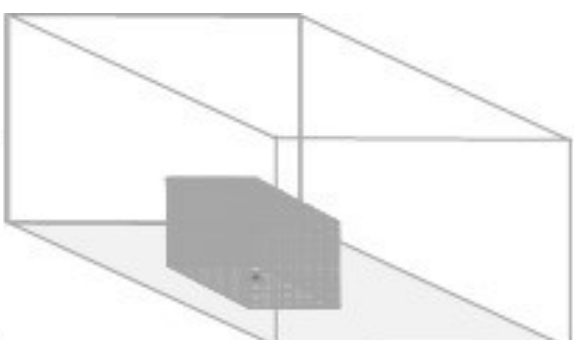

Ratoeira sem estresse predatório individual (RI)

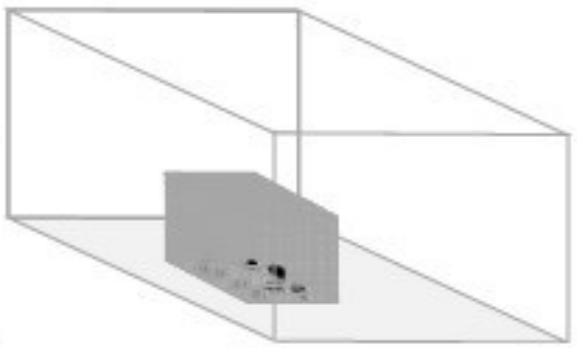

Rato eira sem estresse predatório coletivo (RC)

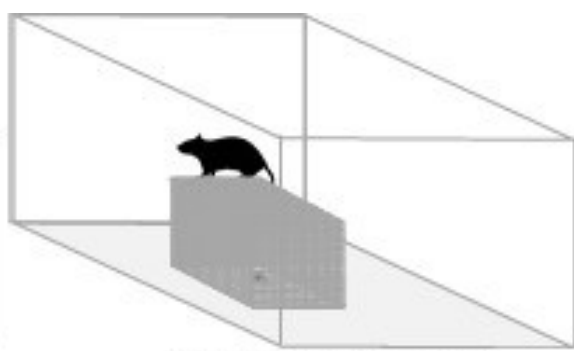

Estresse predatório individual (EPI)

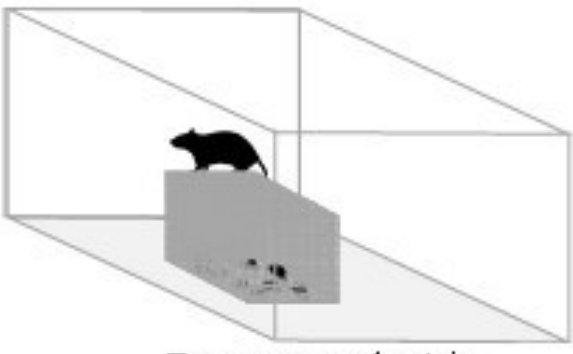

Estresse predatório coletivo (EPC)

Figura 1. Grupos experimentais submetidos ou não ao protocolo de estresse predatório, utilizando rato Wistar. Grupos: CI - Controle individual (n=10), CC - Controle coletivo $(\mathrm{n}=10)$, RI - Ratoeira sem estresse predatório individual $(\mathrm{n}=10), \mathrm{RC}$ - Ratoeira sem estresse predatório coletivo ( $=10)$, EPI estresse predatório individual $(n=10)$ e EPC - estresse predatório coletivo $(n=10)$.

Os camundongos foram mantidos em contato indireto com os ratos Wistar por 12 dias consecutivos, durante uma hora por dia (entre $14 \mathrm{~h}$ e $15 \mathrm{~h}$ ). Os camundongos foram expostos à visão, audição, olfato e efeitos físicos produzidos pelo agente estressor. 0 teste ocorreu em um ambiente controlado (um quarto escuro, onde o ruído externo e ir e vir de pessoas durante o teste de estresse foram evitados). Ressalta-se que foi introduzido apenas um rato por caixa, evitando que houvesse interação entre os ratos, desviando a atenção do predador em relação à presa. Foi conduzida alternância de ratos, evitando que o mesmo rato fosse o predador do mesmo camundongo em exposições diferentes, excluindo possíveis aclimatações predador-presa.

\subsection{Teste comportamental}

Após o período de estresse predatório, o comportamento preditivo de ansiedade dos camundongos foi analisado por meio do teste de labirinto em cruz elevado (LCE) por ser um teste adequado para avaliar os efeitos permanentes da tensão predadores (Beck et al. 2000). 0 LCE utilizado neste estudo possui dois braços abertos $(30,0 \mathrm{~cm} \times 5,0 \mathrm{~cm} \times 0,25 \mathrm{~cm})$, com bordas de acrílico e dois braços fechados com paredes opacas $(30,0 \mathrm{~cm} \times 5,0 \mathrm{~cm} \times 15,5 \mathrm{~cm})$, unidas por uma plataforma central ( $5 \mathrm{~cm} \times 5 \mathrm{~cm})$, sendo os braços elevados 45 cm acima do chão. Na sala de testes, a iluminação foi mantida a 100 lux. Os camundongos foram avaliados individualmente por cinco minutos de exploração livre. Foram avaliados os seguintes parâmetros: número de entradas nos braços abertos e fechados, tempo gasto nos braços abertos e fechados, e o número total de entradas (número de entradas nos braços 
abertos + número de entradas nos braços fechados). Estes parâmetros foram utilizados para calcular o índice de ansiedade, de acordo com a Estrela et al. (2015) da seguinte forma: Índice de Ansiedade = 1 - [C[Tempo nos braços abertos/duração do teste] + [Número de entradas de braços abertos/número total de entradas])/2].

\subsection{Análise estatística}

Os dados foram submetidos inicialmente aos testes de normalidade de Shapiro-Wilk's e homocedasticidade de Bartlett's. Após o cumprimento dos pressupostos foi conduzida analise de variâncias de duas vias (two way ANOVA) para os fatores estresse predatório (ausência ou presença do rato Wistar) e coletividade (animais expostos individualmente ou coletivamente) seguido do teste de Tukey, ambos a 5\% de probabilidade utilizando o software ASSISTAT, versão 7.7 beta.

\section{Resultados e discussão}

Após os 12 dias experimentais não foram observadas diferenças entre os animais expostos ao estresse predatório, expostos à ratoeira e caixa escura e os grupos controles, tanto quando expostos individualmente, quanto expostos de forma coletiva. Também não foram observadas diferenças entre os grupos controle individual e coletivo, bem como entre os grupos ratoeira sem estresse predatório individual e coletivo. Entretanto, foi observada diferença estatística entre os grupos submetidos ao estresse predatório de forma coletiva e individual (Figura 2).

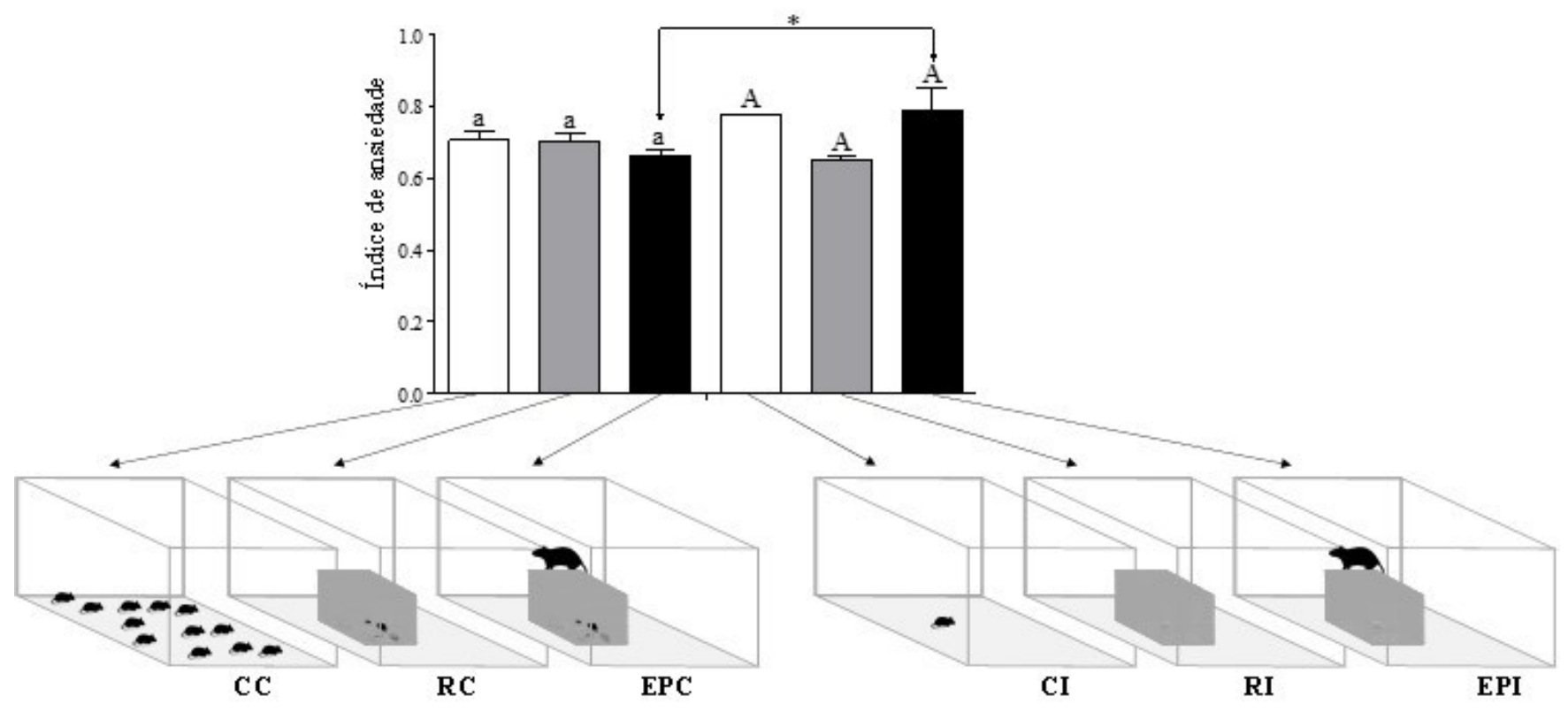

Figura 2. Índice de ansiedade de camundongos Swiss submetidos a estresse predatório pela presença de macho de ratos Wistar, individualmente ou coletivamente. * indica diferença estatística entre EPC e EPI pelo teste two way ANOVA, seguido de teste de Tukey a 5\% de probabilidade. Grupos: CI Controle individual $(n=10), C C$ - Controle coletivo $(n=10)$, RI - Ratoeira sem estresse predatório individual ( $n=10)$, RC - Ratoeira sem estresse predatório coletivo $(n=10)$, EPI - estresse predatório individual $(n=10)$ e EPC - estresse predatório coletivo (n=10).

Estes resultados divergem dos achados de outros estudos envolvendo estresse predatório em camundongos como Miura et al. (2011) e Guimarães et al. (2016). No estudo de Miura et al. (2011) foi utilizado um protocolo de estresse inescapável no qual o agente estressor considerado severo, ocasionou efeitos duradouros sobre o comportamento de camundongos jovens (4 semanas de idade). No presente estudo foi utilizado um protocolo de estresse predatório leve, o que pode explicar as diferenças encontradas, uma vez que a intensidade do agente estressor está diretamente ligada ao aparecimento de comportamentos ansiosos (Miura et al., 2011).

Em relação ao estudo de Guimarães et al. (2016), os autores utilizaram um protocolo muito semelhante ao do presente, com exposição também por 12 dias, sendo este eficiente em induzir ansiedade em camundongos C57BL/6J expostos coletivamente. Contudo, apesar da semelhança entre os protocolos, existem diferenças que podem explicar os resultados divergentes, como as linhagens utilizadas nos estudos (C57BL/6J e Swiss) e o número de ratos utilizados como estressores. As divergências entre diferentes linhagens são conhecidas e reforçadas na literatura, de modo que é necessário ponderar as especificidades de cada linhagem ao compará-las (Griebel et al., 2000; Brooks et al., 2005). Em relação ao número de ratos utilizados no estudo de Guimarães et al. (2016), que foi três vezes maior que no presente estudo, podendo representar um agente estressor mais severo que o utilizado no presente estudo. Dessa forma, os resultados destes estudos, realizados em condições muito semelhantes, mas variando o número de ratos, pode indicar a existência de uma possível relação dose resposta com o número de predadores utilizados, contudo, deve-se levar em conta as diferenças entre linhagens discutidas anteriormente.

Apesar das divergências com outros estudos, os resultados encontrados demonstraram que camundongos expostos ao estresse predatório de forma individual são mais suscetíveis ao desenvolvimento de ansiedade, quando comparados aos expostos coletivamente, reforçando uma visão relativamente previsível, mas de significativa importância para o desenvolvimento de modelos de estudo de ansiedade. Nesse sentido, se faz necessário o desenvolvimento de novos estudos envolvendo o estresse predatório como indutor de ansiedade, que levem em consideração a maior suscetibilidade dos animais quando expostos individualmente e a possível relação dose resposta com o número de predadores utilizados nos estudos.

\section{Referências}

Adamec, R., et al., Lasting anxiogenic effects of feline predator stress in mice: sex differences in vulnerability to stress and predicting severity of anxiogenic response from the stress experience. Physiol. \& Behav., 2006, 88(1-2), 12-29.

Beck, J. A., et al., Genealogies of mouse inbred strains. Nature Genetisc., 2000, 24(1), 23-25. 
Brooks S. P. et al. Behavioral profies of inbred mouse strains used as transgenic backgrounds. II: cognitive tests. Genes Brain Behav. 2005, 4(5), 307-317.

Burgado, J., et al., Two weeks of predatory stress induces anxiety-like behavior with co-morbid depressive-like behavior in adult male mice. Behav. Brain Res. 2014, 275, 120-125.

Estrela, D. C., et al., Predictive behaviors for anxiety and depression in female Wistar rats subjected to cafeteria and stress. Physiol. \& Behav., 2015, 151, 252-263.

Griebel G. et al. Differences in anxiety-related behaviours and in sensitivity to diazepam in inbred and outbread strains of mice. Psychopharmacology (Berl), 2000, 148(2), 164170.

Guimarães A. T. B., Souza, J. M.; Silva, W. A. M.; Mendes, B. O.; Queiroz, J. G.; Castro, A. L. S.; Malafaia G. Novel predatory stress paradigm to induce anxiety-like behavior in juvenile male C57BL/6J mice. Current Science, 2016, (in press).

Miura, H. et al., Long-lasting effects of inescapable-predator stress on brain tryptophan metabolism and the behavior of juvenile mice. Stress, 2011, 14(3), 262-72.

Nunes, E. A. and Hallak, J. E. C. Modelos animais em psiquiatria: avanços e desafios. Rev. Latino Am. Psicopatol., 2014, 17(3), 528-43. 